\title{
Using Explicit Solver while designing the experiment to realize optimized processing parameters for shot-peening
}

\author{
Shreedhar Arasule* and S.R. Patil \\ ${ }^{1}$ Department of Mechanical Engineering (Automotive), SPPU, Pune, Maharashtra, India
}

Accepted 15 June 2016, Available online 20 June 2016, Special Issue-5 (June 2016)

\begin{abstract}
The Shot peening is the most economical process for enhancing the surface characteristics among alternative processes akin to honing, polishing and burnishing. It is the method of inducing residual stress and work hardening on the surface by mechanical yielding. The major applications of shot peening process area unit concerning improvement and restoration of surface and mechanical properties. It also improves the irresponsibleness of machine components by enhancing the mechanical properties. It is the method involving multiple and ferrous components however largely used on steel surfaces. It is the method involving multiple and progressive repeated impacts. The steel balls or shots are thrown against the surface either by compressed air or by force reckoning on the sort of machine. The intensity of the method will be varied by regulating the process parameters i.e. size of shot, the hardness of shot, the speed at which it is laid-off, the length of time, the distance of nozzle from the surface, the angle of the nozzle and the work exposed to the shot.
\end{abstract}

Keywords: Fatigue life, Endurance testing, Shot Peening, Fatigue mechanism, Piston, Residual stress, FEA, Al Alloy

\section{Introduction}

Engineering components and structures are frequently subjected to cyclic loading and they are consequently cause fatigue harm. In most cases, fatigue damage can initiate at the surface due to localized stress concentrations caused by machining marks, exposed inclusions or even because of the contrasting movement of dislocations. Evidently, control over the initiation and early propagation of surface cracks is dominant for prolonging the fatigue life of parts. Shot peening is cold working method that is extensively used in automotive and craft industries for the on top of purpose because it produces close to surface plastic deformation resulting in the event of work-hardening and high magnitude compressive residual stresses. Work hardening is expected to extend the flow resistance of the fabric and thus scale back crack tip physical property, while, the residual stresses can act as: a) mean stress modulators within the case of the onset of crack propagation or b) closure stress in the case of crack growth.

Shot peening is viewed as a process involving multiple and more and more recurrent impact. In this process, the result is accomplished by bombarding relatively arduous particles, usually spherical chilled shots having impact velocities go from twenty to one hundred fifty $\mathrm{m} / \mathrm{s}$. They are projected against the

*Correspoding author: Shreedhar Arasule surface being peened with ample velocities to indent the surface. The process has helpful applications in increasing fatigue strength, relieving tensile stresses. Aerospace business has explicit applications of metal alloys. Typical applications include body skin, wing ribs, bulkheads, leading gear beam and wing lower skin of aircraft. Helicopter rotor blades and some components of their drive parts, high pressure turbine and mechanical device discs. Some of these parts are made from metal alloy 2024. Fatigue life of these components is one in every of the most important issues. Shot peening is one of the methods to enhance the fatigue life. Its effectiveness is depends upon parameters like coverage, shot size, shot distance, exposure time, intensity, shot velocity etc. so for this optimization of parameters is necessary.

\subsection{Shot Peening Parameters}

The shot peening process is a difficult mechanism in materials science, despite a long history and an oversized number of investigations into the method it's still characterized by several areas of uncertainty. The study of the different parameters concerned in shot peening applications is very important so as to possess higher understanding and management of such method. The shot peening method has to be exactly controlled and repeatable process for optimum profit. To achieve this, all its process variables should be known and controlled. There are several basic parameters poignant the shot peening method. 


\subsection{Drawback Definition}

The crack initiation and propagation normally starts at the surface of the part beneath stress. Tensile stresses are harmful to the life of the part because the crack notices a good path to continue its growth. Residual Compressive stresses on the other hand will effectively curb the harmful effects and cause an increased lifetime of the part whereas subjected to stresses throughout its operation. Applications prone to failure because of cyclic or reversible loading may gain advantage from the cold working method of Shot Peening. Excessive time is consumed in experimenting with the known parameters for realizing the desired result by standard ways of trial and error.

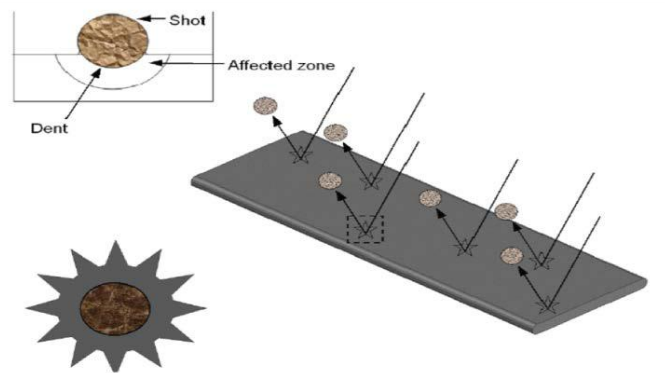

Fig. 1 Schematic Diagram of Shot Peening

\subsection{Methodology}

Proposed work aims to investigate the impact of exploitation express thinker whereas coming up with the experiment to comprehend optimized process parameters for shot-peening. The proposed work is planned to be carried out in following distinct phases, steps in project execution given below;

a. Study alternative processes for life improvement

b. Study shot peening method

c. Development of FE model for shot peening

d. Shot peening on component

e. Comparison of results

f. Recommendations

\section{Literature Review}

In light of the residual stress profile, the magnitude of the strain hardening and the corresponding amount of surface roughening, it is realistic to assume that CSP will principally have an effect on the stages of fatigue harm that correspond to the initiation and propagation of short cracks. It is proved and recorded that the on top of stages are liable for over seventieth of the fatigue lifetime of a part (Suresh S., 1991)

Crack initiation is a controversial subject, which for any years provided the ground for various completely different theories particularly within the case of single crystals. In polycrystalline materials, where most business alloys are classified, crack initiation is assumed to occur almost like a shot the part is loaded at stresses on top of the fatigue limit thence, the crack initiation stage can be seen because the early propagation of a crack from the materials microdefects (Miller 1993, Kitagawa et al 1976).

The shot peening process is a difficult mechanism in materials science, despite a long history and an oversized number of investigations into the method it's still characterized by several areas of uncertainty. The study of the different parameters concerned in shot peening applications is very important so as to possess higher understanding and management of such method. The shot peening method has to be a exactly controlled and repeatable process for optimum profit. To achieve this, all its process variables should be known and controlled. There are several basic parameters poignant the shot peening method.

According to Franck Petit-Renaud (2002) the foremost common parameters are as follows;
a. Shot Density
b. Hardness of the shot
c. Shot Size
d. Nozzle diameter
e. Air Pressure
f. Impact Angle
g. Distance from nozzle to work-piece.
h. Exposure time
i. Number of passes

j. Linear and rotational speed of work-piece relative to nozzle

k. Shot Velocity.

\section{1 outline of Literatures studied}

a) Considerable amount of experimental work is carried out on shot peening of Al 2024 alloy for fatigue life.

b) Less work is reported on shot peening optimization parameters.

c) Many researchers have used shot peening method with success to improve fatigue life.

d) Most relevant parameters are shot speed, shot dia., exposure time, shot distance and shot distance.

e) Experimental work can be expeditiously used for fatigue life prediction.

f) Finite element model will be wont to predict residual stresses when shot peening.

g) Fatigue life prediction is very complicated method because it involves such a big amount of parameters at identical time like material, applied load type, surface finish, environment, induced stresses etc.

h) Higher applied stress will offer lower fatigue life.

i) Surface finish plays important role in fatigue life as it is expounded with crack initiation and crack propagation.

j) Compressive residual stresses improve the fatigue life where as tensile residual stresses can scale back fatigue life.

k) High residual stresses do not implies higher fatigue life all the time. 
l) Various applied type of masses in fatigue provides completely different pattern behavior.

m) Past information can facilitate up to some extent for prediction of fatigue life.

\section{2 analysis Issues}

Based on the literature review following analysis problems are evolved,

i. Shot peening has beneficial effects on the completely different grades of metal alloys. But over peening could harm the surfaces and less peening won't improve fatigue life in desired quantity.

ii. Majority of the researchers have carried out experimental work for analyzing the effect of shot peening on fatigue lifetime of metal. Also there are substantial variations between the findings of the varied experiments within the fatigue life prediction of for peened parts, this need to be investigated.

iii. The shot peening process involves range of parameters such as shot size, shot material, shot quality, pressure/velocity, exposure time, peening distance etc, that need to be controlled. Shot peening process heavily depends upon condition or peening parameters. But it remains unclear however these parameters have an effect on the peening quality and what are the optimum peening conditions for metal alloys.

iv. Experimental optimization of method parameters is high-ticket. Finite element modeling of the method will scale back the experimental expenses and range of iterations requited for optimization.

\section{Design of Experiments (DOE)}

Experiments are performed by investigators in just about all fields of enquiry, usually to discover one thing a few explicit method or system. Literally, an experiment is a check. More formally, define an experiment as a check or series of tests during which purposeful changes are created to the input variables of the method or system so we have a tendency to can observe and determine the explanations for changes which will be discovered in output response. In engineering, experimentation plays a vital role in new product style, manufacturing method development and method improvement. The objective in many cases could also be to develop a strong method, that is, a process affected minimally by external sources of variability.

\section{- Steps in DOE}

a) Planning phase:

A designer learned something from every experiment that can positive or negative. Positive information is AN indication of that issue and that levels ends up in improved method performance. Negative information is an indication of these factors doesn't lead improvement, but no indication of that factors do.

\section{b) Conducting phase}

In this phase, test results are truly collected. If experiments are well planned and conducted then analysis is simpler and provides positive data concerning factors and levels.

c) Analysis phase:

In analysis phase, positive or negative information concerning factors and levels are generated. This phase is most applied mathematics in nature of the 3 phases of the DOE.

\section{- Steps for Taguchi Design of Experiment}

1) State the problem(s) or area(s) of concern:

In this step the matter is stated with its objective yet as purpose. Also throughout this all the necessary data is declared concerning the matter like however the matter is discovered, when drawback happens, how severe the drawback is etc. In our experiment the problem is declared in chapter no 1 . We have to enhance the fatigue lifetime of the fabric with facilitate of shot peening

2) State the objective(s) of the experiment:

We have state the target of the experiment. The objective should be specific for higher experiment designing. We have to enhance the fatigue lifetime of material by distinguishing the parameters and optimize it.

3) Select the quality characteristics and measurement system:

The quality characteristics are to be declared and the way they're to be measured is to be determined. We can live the residual stresses Finite component modeling afterward physical experimentation by hole drill methodology and fatigue life is to be tested by rotating beam bending machine.

4) Select the factors that may influence the chosen quality characteristics:

The factors which influence quality characteristics are to be known. Detailing of method is desired. The shot peening will evoked residual stress in the specimen. Residual stress will improve the fatigue life. Residual stress is controlling parameter for fatigue life. As per literature review, Shot size, Shot Velocity, Impact Angle \&amp; Shot Distance are the most influential parameters on residual stresses.

5) Identifying the Control and Noise factors:

In this step, all the control factors and noise factors are determined. Noise factors are not controlled or terribly high-ticket to manage or tough to manage. We have to explain the management factors in previous step. Noise factors in shot peening are heat energy created within the method, wear of shot during the method, unavoidable interference of shots, producing cracks in weak sections.

6) Select levels of the factors:

The levels of things are hand-picked within the experiment. The experiment should be possible with the given levels. In our particular experiment, 4 levels 
are hand-picked. Means every issue can have four values.

- $\quad$ Shot size in $\mathrm{mm}$ - zero.65, $0.75,1,1.25$

- Shot Velocity in $\mathrm{m} / \mathrm{s}$ - thirty, $40,45,60$

- $\quad$ Shot Impact angle in degrees- $45,65,80,85$

- Shot distance in mm- 90, 120, 150, 190.

7) Select the appropriate orthogonal array:

The proper array should be hand-picked for proper experiment. This will produce correct iterations for the experiment. So for four Level and four management Factors we have a tendency to hand-picked L16 Orthogonal Array in out there choice.

8) Assign Factors to OA and locate interactions:

In this step $\mathrm{OA}$ is made and iterations are determined. L16 OA was created as per table 4.1 with Minitab package

9) Conduct the tests described by trials in OA:

In this we've to require trials/iterations as per OA. The trials are then done in FEM with facilitate of HyperMesh \& amp; LS-Dyna.

10) Analyze the Results of experimental trials:

The results are to be analyzed by appropriate methodology. In this we've to maximize the residual stress and reduce the noise factors. So we have a tendency to have chosen larger is best kind the $\mathrm{S} / \mathrm{N}$ quantitative relation.

11) The Conduction of confirmation experiment:

The conduction of confirmation experiment is the last step in DOE. If conduction experiment provides desired results, the experimentation carried out is correct, otherwise reconstruct the experiment.

In this if optimize result with larger the higher $\mathrm{S} / \mathrm{N}$ quantitative relation provides most residual stress compared with the other trial/iteration, the experiment carried out is alleged to be perfect. Also, fatigue life testing was carried out on specimen with optimized set of parameters.

\section{Fatigue Life Prediction}

The parts under fatigue loadings are considered to fail much below the yield strength of the material. In critical applications like aeronautics, engines or where part failure means losing of human lives; prediction of accurate fatigue life is of prime importance.

- The higher gain like Xiang model is not possible in our case since the displacement is foreseen by FEM is from sixty microns to seventy microns for the iteration sets.

- We can predict by residual stress impact solely as per scope \&amp; experimentation limitations.

- $242 \mathrm{MPa}$ induced stress is close to Iterations like 275,232 \&amp; $225 \mathrm{MPa}$, but they are not precise to our iterations. Also Mehmood used completely different shot peening conditions, so the results can't be applied because it is.

- Also applied range of stress is different (215 $\mathrm{MPa}$ ) than we have a tendency are applied

- So we will predict following things
- No high gain as Xiang is possible

- The gain (\%) predicted in five hundredth vary

Table 1 Fatigue Life Prediction

\begin{tabular}{|c|c|c|c|}
\hline $\begin{array}{c}\text { Residual } \\
\text { Stresses } \\
\text { (Actual) }\end{array}$ & $\begin{array}{c}\text { Disp. in } \\
\text { Micron } \\
\text { (FEA) }\end{array}$ & $\begin{array}{c}\text { Applied } \\
\text { stress } \\
\text { range }\end{array}$ & $\begin{array}{c}\text { Predicted } \\
\text { Gain (\%) }\end{array}$ \\
\hline 275 & 67 & 215 & $160-210$ \\
\hline 232 & 66 & 215 & $150-200$ \\
\hline 225 & 62 & 215 & $140-190$ \\
\hline
\end{tabular}

\section{Experimentation}

In this chapter various observation observed during experimentation are tabulated

\subsection{Process parameter selection}

Table 2 Experimentation Iterations

\begin{tabular}{|c|c|c|c|}
\hline $\begin{array}{c}\text { Shot } \\
\text { Size }\end{array}$ & $\begin{array}{c}\text { Velocity } \\
\mathrm{m} / \mathrm{s}\end{array}$ & $\begin{array}{c}\text { Impact } \\
\text { angle }\end{array}$ & $\begin{array}{c}\text { Distance } \\
\mathrm{mm}\end{array}$ \\
\hline 1.25 & 60 & 45 & 120 \\
\hline 1.25 & 60 & 45 & 190 \\
\hline 1.25 & 60 & 45 & 150 \\
\hline
\end{tabular}

The exposure time is set constant, equal to $120 \mathrm{sec}$ for all specimens as it will have $100 \%$ coverage

\section{- Specimen Composition}

The project has been carried out to improve the fatigue life of Al-2024 material by shot peening method. The material composition is shown in Table 5.2 below

Table 3 Specimen Composition

\begin{tabular}{|c|c|}
\hline Name of Content & Concentration \\
\hline Aluminum & $94-91 \%$ \\
\hline Copper & $3.8-4.9 \%$ \\
\hline Magnesium & $1.2-1.8 \%$ \\
\hline Silicon & $0.50 \%$ \\
\hline Iron & $0.50 \%$ \\
\hline Manganese & $0.3-0.9 \%$ \\
\hline Zinc & $0.25 \%$ \\
\hline Titanium & $0.15 \%$ \\
\hline Chromium & $0.1 \%$ \\
\hline
\end{tabular}

- Shot Peening Procedure

1) Feed the shots through hopper.

2) Adjust valve for desirable flow rate of shots.

3) Load the standard test specimen in fixture (It will expose half part of specimen) and close the door.

4) Set the air speed for desirable shot speed.

5) Set the cycle time.

6) Start the cycle.

Open the door after cycle completion and run same cycle for remaining half portion of specimen.

Repeat the procedure for another specimen.

9) Set the new shot speed and repeat the procedure. 


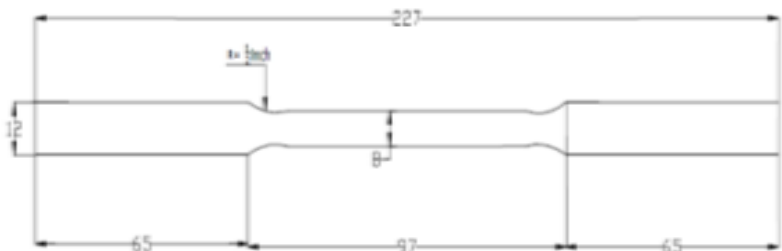

Fig.2 Test Specimen for Fatigue Testing

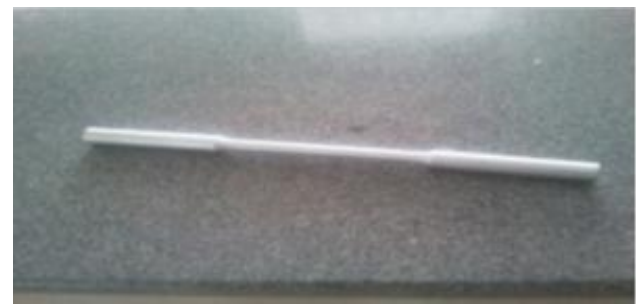

Fig. 3 Standard non peened specimen

- $\quad$ Fatigue testing procedure

1) Fix the standard test specimen in machine chuck.

2) Apply load through weight hanger.

3) Run the machine till specimen gets fractured.

4) Record the reading from cycle counter.

5) Repeat the procedure for next specimen.

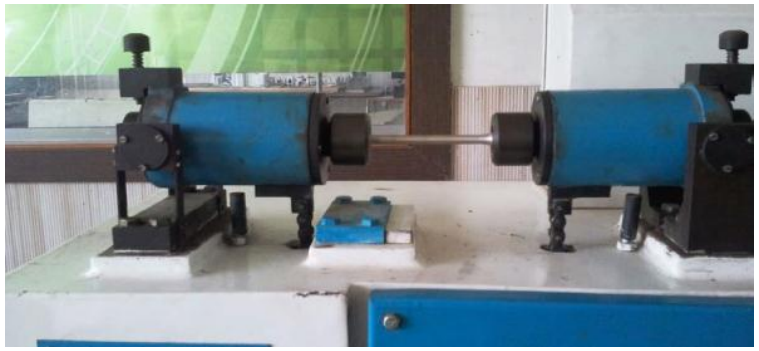

Fig. 4 Fatigue Testing Machine Setup

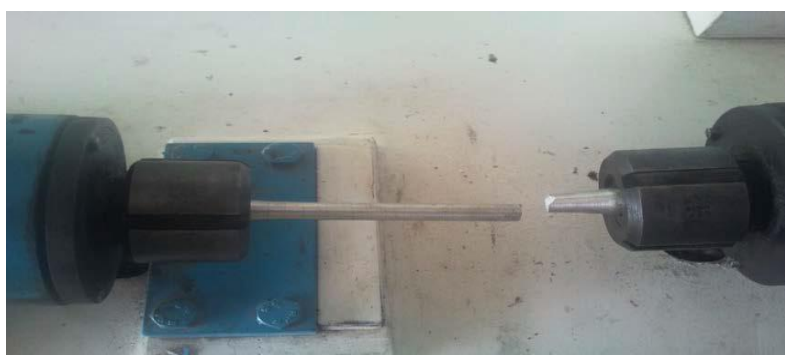

Fig. 5 Fatigue Testing Failure of Specimen

\section{Results and Discussion}

Table 4 Residual Stress \& FEM calculated stress

\begin{tabular}{|c|c|c|c|}
\hline $\begin{array}{c}\text { Test } \\
\text { Specimen }\end{array}$ & $\begin{array}{c}\text { Residual } \\
\text { Stresses } \\
\text { (FEA) }\end{array}$ & $\begin{array}{c}\text { Residual Stresses } \\
\text { (Hole Drill } \\
\text { method) }\end{array}$ & $\begin{array}{c}\text { Error } \\
\%\end{array}$ \\
\hline 1 & 324 & 275 & 15.2 \\
\hline 2 & 258.87 & 232 & 10.38 \\
\hline 3 & 256.1 & 225 & 12.15 \\
\hline
\end{tabular}

There were 3 shot peening sets were selected from FEM to carry out experimentation. Shot size 1.25, shot velocity $60 \mathrm{~m} / \mathrm{s}$, impact angle $45^{\circ}$, shot distance 120 mm gives $275 \mathrm{MPa}$ stress against $324 \mathrm{MPa}$ of FEM. Shot size 1.25 , shot velocity $60 \mathrm{~m} / \mathrm{s}$, impact angle $45^{\circ}$, shot distance $100 \mathrm{~mm}$ gives $225 \mathrm{MPa}$ stress against 256.1 $\mathrm{MPa}$ of FEM. Shot size 1.25, shot velocity $60 \mathrm{~m} / \mathrm{s}$, impact angle $45^{\circ}$, shot distance $150 \mathrm{~mm}$ gives $232 \mathrm{MPa}$ stress against 258.87 MPa of FEM. So the error varies from 10.38 to $15.2 \%$. In case of rotating beam fatigue testing the specimens improved their fatigue life with help of shot peening with gain of $168.75 \%$ to $180 \%$.

Table 5 Results of Fatigue Testing

\begin{tabular}{|c|c|c|c|}
\hline $\begin{array}{c}\text { Specimen } \\
\text { type }\end{array}$ & Fatigue life & $\begin{array}{c}\text { Predicted } \\
\text { gain (\%) }\end{array}$ & $\begin{array}{c}\text { Actual } \\
\text { gain (\%) }\end{array}$ \\
\hline Original & $1.6 \times 105$ & -- & -- \\
\hline Peened 1 & $4.35 \times 105$ & $160-210$ & 171.87 \\
\hline Peened 2 & $4.48 \times 105$ & $150-200$ & 180 \\
\hline Peened 3 & $4.3 \times 105$ & $140-190$ & 168.75 \\
\hline
\end{tabular}

\section{Conclusion}

This study carried out on Al 2024 alloy. Conclusions from the study are given below;

1. For the particular given set of values of parameters Shot Size $1.25 \mathrm{~mm}$, Shot Velocity $60 \mathrm{~m} / \mathrm{s}$, Impact angle $45^{\circ}$ and Shot Distance $90 \mathrm{~mm}$ is the optimum parameter set. The deflection for this was 68.9 microns. Immediate stress was $1100 \mathrm{MPa}$. Residual stress is $356.6 \mathrm{MPa}$ for this.

2. Single impact modeling of shot peening showed good agreement with experimental results. When the actual peened parts were check maximum error was of $15.2 \%$

3. Fatigue life prediction was carried out for $\mathrm{Al} 2024$ by past data available for the material and present peening condition in $50 \%$ gain accuracy.

4. The fatigue life's predicted gain was from $150 \%$ to $200 \%$.

5. The fatigue life gain was varied from $168.75 \%$ to $180 \%$ for the peened specimens.

6. The behavior of the parameters can be seen by $\mathrm{S} / \mathrm{N}$ ratio graphs with strategy Larger the better.

7. The measurement of residual stress was done by hole drill method. The actual results are in range of $84.8 \%$ to $89.62 \%$ of Finite Element Modeling iterations which checked by physical experimentation.

8. The fatigue life was checked by rotating beam bending machine. The fatigue life gain was $168.75 \%$, $171.87 \%$ \& $180 \%$ for the specific peened components.

9. It is seen that there is very less effect of shot peening on residual stresses below $1 \mathrm{~mm}$ from peened surface. 


\section{References}

Rodopoulos, Curtis, Rios, Solis Romero (2004), Optimization of the fatigue resistance of 2024-T351 aluminum alloys by controlled shot peening- methodology, results and analysis, International Journal of Fatigue.

Romero, Rios, Fam, Levers (1999), Optimization of the shot peening process in terms of fatigue resistance, Conf Proc: ICSP-7, Warsaw, Poland.

Y.F. Al-Obaid (1995), Shot Peening Mechanics: experimental and theoretical analysis, Mechanics of Materials.

S. Wang, Y. Li, m. Yao, R. Wang (1998), Compressive residual stress introduced by shot peening, Journal of Materials Processing Technology.

S.B. Mahagaonkar, Dr. P.K. Brahmankar, C.Y. Seemikeri (2009), Influence of shot peening parameters on fatigue life and surface hardness of AISI 1045 materials, IE journal$P$

Meguid S.A, Shagal G, Stranart JC, Daly J. (1999), Threedimensional dynamic finite element analysis of shotpeening induced residual stresses, Finite Element Analysis.

Renaud (2002), Optimization of Shot peening Parameters, Conf Proc: ICSP-8, Garmisch-Partenkirchen, Germany.

R. Menig, V. Schulze, D. Lohe, O. Vohringer (2002), Shot peening plus subsequent short time annealing-a way to increase residual stress stability and alternating bending strength of AISI 4140, Society of automotive engineers.

Guagliano M, Vergani L, Bandini M, Gili F. (1999), An approach to relate the shot peening parameters to the induced residual stresses, Conf Proc: ICSP-7, Warsaw, Poland.

Ludian and Wanger (2005), Coverage Effects in Shot Peening of Al 2024-T4, Conf Proc: ICSP-9, Paris, France.
Rahman M.M., Ariffin A.K., Jamaludin N., Haron H.C. (2006), Influence of surface treatments on fatigue life a two stroke free piston linear engine component using random loading, Journal of Zhejiang University.

M.L. Agarwal, V.P. Agrawal , R.A. Khan (2006), A stress approach model for predictions of fatigue life by shot peening of EN45A spring steel., International journal of fatigue.

George Leghorn (1957 Nov.), The story of shot peening, A.S.N.E. Journal, pp 653- 666.

Shengping Shen, S. N. Atluri (2006), An analytical model for shot-peening Induced Residual Stresses, CMC, vol.4, no.2

S. Curtis, E.R. de los Rios, C.A. Rodopoulos, A. Levers (2003), Analysis of the effects of controlled shot peening on fatigue damage of high strength aluminum alloys, International Journal of Fatigue.

Arshad Mehmood and M.M.I. Hammouda (2007), Effect of Shot Peening on the Fatigue Life of 2024 Aluminum Alloy, Failure of Engineering Materials \& Structures.

A. Inoue, T. Sekigawa, K. Oguri (2008), Fatigue property enhancement by fine particle shot peening for aircraft aluminum parts, Conf Proc: ICSP-10, Tokyo, Japan

R. Uros Zupanc and Janez Grum (2011), Surface Integrity of Shot Peened Al Alloy 7075-T651, Journal of Mechanical Engineering.

Zhou Wang, Chuanhai Jiang, Xiaoyan Gan, Yanhua Chen, Vincent Ji (2011), Influence of shot peening on the fatigue life of laser hardened 17-4PH steel, International Journal of Fatigue.

K. Dalaei, B. Karlsson (2012), Influence of shot peening on fatigue durability of normalized steel subjected to variable amplitude loading, International Journal of Fatigue. 